\title{
Assessing requirements and improving food provision to a young adult inpatient cancer ward
}

\author{
R. C. Wolfenden \\ Department of Nutrition and Dietetics, Leeds Teaching Hospitals, LS9 7TF, UK
}

Malnutrition and weight loss are common in cancer and can affect treatment response, increase the incidence of therapy-related side effects and ultimately reduce survival. Within a nine-bedded ward for young adults (YA) with cancer, it was questioned whether food provision via standard catering services was able to meet the needs of this patient group. It was becoming evident from practice that YA inpatients with cancer were likely to have higher nutritional requirements as a result of their age and typically increased activity/mobility levels compared to older inpatients. The aim of this project was to determine patient nutritional requirements and understand YA inpatient food preferences in order to better meet their dietary needs.

Daily energy requirements were calculated using prediction equations ${ }^{(1)}$, adjusted for stress and activity. Protein requirements were estimated as per standard UK dietetic practice. These requirements were compared with those of matched controls aged 60-74 years and with the hospital daily meal and drink provision standard. Estimated requirements were calculated for 11 patients (mean age 21.8 years). At an activity level of $25 \%$ (Table) YA required approximately $10 \%$ more energy per day to maintain weight than older adults, whereas at $40 \%$ activity (not shown) this increased to an additional $25 \%$ energy per day.

\begin{tabular}{|c|c|c|c|}
\hline Age (years) & $18-24$ & $60-74$ & Mean difference \\
\hline Male $(n 8)$ (activity level $25 \%$ ) & $9422.37 \mathrm{~kJ} / \mathrm{d}(2252 \mathrm{kcal} / \mathrm{d})$ & $8663.82 \mathrm{~kJ} / \mathrm{d}(1999 \mathrm{kcal} / \mathrm{d})$ & $+1058.55 \mathrm{~kJ} / \mathrm{d}(+253 \mathrm{kcal} / \mathrm{d})$ \\
\hline Female (activity level 25\%) & $7702.74 \mathrm{~kJ} / \mathrm{d}(1841 \mathrm{kcal} / \mathrm{d})$ & $6957.99 \mathrm{~kJ} / \mathrm{d}(1663 \mathrm{kcal} / \mathrm{d})$ & $744.75 \mathrm{~kJ} / \mathrm{d}(+178 \mathrm{kcal} / \mathrm{d})$ \\
\hline
\end{tabular}

YA nutritional requirements were not fully met by the current hospital food service.

\begin{tabular}{|c|c|c|c|}
\hline & Daily hospital food and drink standard & Mean requirements* (male) & Mean requirements* (female) \\
\hline Energy & $\begin{array}{l}5020.8-5230 \mathrm{~kJ} / \mathrm{d} \\
\quad(1200-2500 \mathrm{kcal} / \mathrm{d})\end{array}$ & $\begin{array}{c}9422.37-10560.42 \mathrm{~kJ} / \mathrm{d} \\
\quad(2252-2524 \mathrm{kcal} / \mathrm{d})\end{array}$ & $\begin{array}{r}7702.74-8556.28 \mathrm{~kJ} / \mathrm{d} \\
(1841-2045 \mathrm{kcal} / \mathrm{d})\end{array}$ \\
\hline Protein $(\mathrm{g} / \mathrm{d})$ & $55-60$ & $70-82$ & $63-74$ \\
\hline
\end{tabular}

*Range indicates mean calculated requirements for 25 and $40 \%$ activity levels.

YA opinions about inpatient food provision and their dietary habits (e.g. food types eaten and meal timings) were determined using a questionnaire and food diary. A number of reasons were identified as to why hospital food and drink provision did not meet YA dietary needs and preferences.

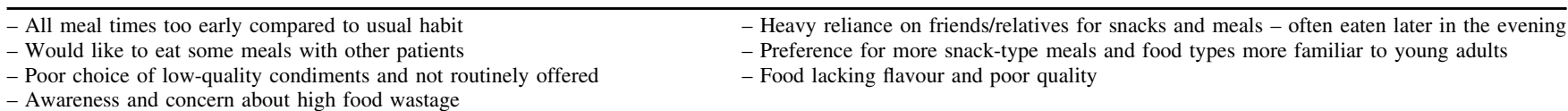

This project has resulted in significant changes being implemented to achieve more flexible provision of food types and quantities, to help meet the nutritional needs of this patient group. The project has also raised awareness among the multi-professional team regarding the importance of nutritional screening and management of nutrition in YA patients with cancer.

1. Department of Health (1991) London: HMSO. 